\title{
MESTRADO PROFISSIONAL EM ENSINO DE BIOLOGIA E COTIDIANO DOCENTE: REFLEXÕES COMPARTILHADAS SOBRE AVALIAÇÃO DA APRENDIZAGEM
}

PROFESSIONAL MASTERS IN BIOLOGY TEACHING AND TEACHER'S DAILY: SHARED REFLECTIONS ON LEARNING ASSESSMENT DOCENTE: REFLEXIONES COMPARTIDAS SOBRE LA EVALUACIÓN DEL APRENDIZAJE

Marcia Taborda*
Juliana Nogueira de Souza**
Whitaker Jean Jaques
e Silva***
Paulo Bomtempo Júnior****
Ana Cristina Jorck*****
Luiz Antônio Cidral
da Costa*****

*Doutora em Ciências Médicas, mestra em Educação e especialista em Avaliação Educacional pela Universidade do Estado do Rio de Janeiro (UERJ), onde é docente da Faculdade de Formação de Professores e do Mestrado Profissional em Ensino de Biologia (ProfBio). Rio de Janeiro,

Rio de Janeiro, Brasil.

E-mail: taborda.marcia@gmail.com

**Discente do Mestrado Profissional em Ensino de Biologia em Rede Nacional (ProfBio) pela Universidade Estadual de Campinas (UNICAMP), especialista em Educação Empreendedora pela Universidade Federal de São João Del-Rei (UFSJ) e docente da rede estadual de São Paulo. Piracicaba, São Paulo, Brasil. E-mail: juliana.fcav@gmail.com

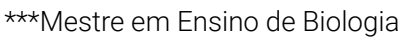
pela Universidade do Estado do Rio de Janeiro (UERJ), especialista em Ensino de Ciências e Biologia pela Universidade Federal do Rio de Janeiro (UFRJ), e atual docente das redes municipais de ensino de Duque de
Caxias e do Rio de Janeiro. Rio de Janeiro, Rio de Janeiro, Brasil. E-mail:whijeanjs@gmail.com $\star \star \star \star$ Mestre em Ensino de Biologia pela Universidade Federal de Juiz de Fora (UFJF), especialista em Gestão Ambiental pela Universidade Presidente Antônio Carlos, de Juiz de Fora, e licenciado em Ciências Biológicas pela UFJF. Atualmente, é professor efetivo no Instituto Federal do Sudeste de Minas Gerais - Campus Rio Pomba, Minas Gerais, Brasil.

E-mail: pbomtempo@gmail.com

$\star \star \star \star \star \star$ Mestra em Ensino de Biologia pela Universidade Federal de Santa Catarina (UFSC), bacharela e licenciada em Ciências Biológicas pela UFSC. Atualmente, docente na rede pública de ensino do estado de Santa Catarina. Joinville,

Santa Catarina, Brasil.

E-mail: jorck.anacristina@gmail.com $\star \star \star \star \star \star \star$ Mestre em Ensino de Biologia pela Universidade Federal de Santa Catarina (UFSC), licenciado em Ciências de $1^{\circ}$ Grau pelo Centro Universitário de Brusque (UNIFEBE) e em Ciências Biológicas pela Universidade do Contestado (UnC). Docente na rede pública de ensino do Estado Santa Catarina e na rede pública de ensino do município de Curitibanos. Curitibanos, Santa Catarina, Brasil.

E-mail: cidralci@gmail.com

Recebido para publicação em: 13.6.2019

Aprovado em: 27.1.2020

\section{Resumo}

Considerando o papel da avaliação da aprendizagem para a educação e partindo das inquietações dos discentes da disciplina Avaliação da Aprendizagem, no Mestrado Profissional em Ensino de Biologia em Rede Nacional, produziu-se o presente artigo, cujo objetivo é compartilhar questões que se apresentam como desafios aos diversos cotidianos educacionais. Ratifica-se a importância de que a avaliação da aprendizagem esteja inserida nos processos de formação dos professores, tendo em vista seu potencial para a aprendizagem significativa e para o desenvolvimento do protagonismo estudantil.

Palavras-chave: Formação de professores. Biologia. Avaliação da aprendizagem. Mestrado profissional. 


\section{Abstract}

Considering the significance of the learning assessment for education and starting from the concerns of students in the Learning Assessment discipline, in the Professional Masters Degree in Biology Teaching in the National Network, this article aims to share issues that present challenges to the different educational everyday activities. It ratifies the importance of the insertion of the learning assessment in the processes of teacher training, given its potential for meaningful learning and the development of student protagonism.

Keywords: Teacher training. Biology. Learning assessment. Professional Masters.

\section{Resumen}

Teniendo en cuenta el papel de la evaluación del aprendizaje para la educación y a partir de las preocupaciones de los estudiantes de la disciplina Evaluación del Aprendizaje, en la Maestría Profesional en Enseñanza de Biología en la Red Nacional, se produjo este artículo, cuyo objetivo es compartir temas que se presentan como retos a las diversas prácticas educativas cotidianas. Se ratifica la importancia de que la evaluación del aprendizaje se inserte en los procesos de formación del profesorado, en vista de su potencial para un aprendizaje significativo y para el desarrollo del protagonismo estudiantil.

Palabras clave: Formación de profesores. Biología. Evaluación del aprendizaje. Maestría Profesional.

\section{Introdução}

Como avaliar? O que avaliar? Como acompanhar realmente a aprendizagem? Será possível um aluno que frequenta as aulas tirar zero em uma atividade avaliativa? Ou seja, ele não aprendeu nada? Mas como ele não aprendeu nada se participou das aulas? Esses são alguns dos questionamentos presentes no cotidiano dos professores das redes públicas e privadas, da educação básica ao ensino superior, independentemente da área em que lecionam.

No ensino de Biologia não seria diferente. Enfrentam-se desafios que exigem do professor preparação e reflexão constantes para que possa superá-los. Um desses obstáculos encontrados refere-se ao fato de os alunos do Ensino Médio apresentarem grande dificuldade na compreensão da importância das relações entre os seres vivos, pois os conteúdos e as metodologias estão na maior parte voltados à preparação para os exames vestibulares, enfatizando a memorização de denominações e conceitos e a reprodução de regras e processos (BRASIL, 2006). Nessa visão, todo o processo pedagógico fica submisso à realização de provas internas e externas, reduzindo o potencial da educação, ao invés de oportunizar uma formação humana mais ampla. 
A avaliação

como forma de

exercício do

poder deve ceder

lugar para uma

análise coerente

com as teorias

contemporâneas
Se o processo pedagógico é voltado para a preparação dos exames, a atual avaliação da aprendizagem é a reprodução na sala de aula das provas seletivas, resultando em uma aprendizagem estatística, não diagnóstica, antidemocrática e autoritária. No entanto, o processo avaliativo precisa superar essas amarras históricas relacionadas à sociedade burguesa (LUCKESI, 2001a). A avaliação como forma de exercício do poder deve ceder lugar para uma análise coerente com as teorias contemporâneas de aprendizagem e de educação, visando ir além de servir à lógica dos rankings que pretendem medir quem é o melhor.

Por meio de estratégias avaliativas, é possível o desenvolvimento de habilidades metacognitivas, no sentido de fortalecer a autonomia e a identidade do estudante, na perspectiva de provocar um saber autônomo, significativo e libertador, fundamental para Freire (1996). Como parte desse processo, "a Biologia pode ser uma das disciplinas mais relevantes e merecedoras de atenção dos alunos, ou uma das disciplinas mais insignificantes e pouco atraentes, dependendo do que for ensinado e de como isso foi feito" (KRASILCHIK, 2008, p. 11).

De acordo com Teixeira (2003), a área de Ciências, de modo geral, sempre se caracterizou pelas abordagens que aprisionam o ensino em um campo epistemológico próprio e restrito aos aspectos conceituais de cada disciplina. Quando se trata do aprendizado da Biologia e das relações com outros conteúdos, as dificuldades aumentam ainda mais. Segundo o autor, vem sendo construída uma visão equivocada da ciência, afastada do cotidiano, desconectada da realidade social, filosófica, política, econômica e ética. Ou seja, é preciso mudar esse contexto, para que o aluno passe a relacionar os conceitos de várias disciplinas de forma mais ampla e tenha condições de discutir e apresentar suas opiniões.

Assim, as inquietações proporcionadas pelas discussões na disciplina eletiva Avaliação da Aprendizagem, ofertada pela Universidade do Estado do Rio de Janeiro (UERJ) para os alunos do Mestrado Profissional em Ensino de Biologia (Profbio) motivaram a escrita deste artigo, cujos autores são professores de Biologia da rede pública em diferentes unidades educacionais do Brasil, além de serem discentes desse curso, ou seja, estão vivenciando o confronto de suas práticas docentes com os aspectos teóricos e vice-versa.

O Profbio é um programa em rede de pós-graduação stricto sensu, na modalidade semipresencial, com oferta simultânea em 18 instituições de ensino superior públicas, federais e estaduais, em 20 campi distintos, distribuídos por 14 estados da federação, além do Distrito Federal. O programa tem como objetivo a qualificação profissional de professores das redes públicas de ensino em efetivo exercício da docência em Biologia, construindo e consolidando conhecimentos biológicos, por meio da metodologia investigativa e da utilização de tecnologias da informação e comunicação, de maneira que os mestrandos possam trabalhar simultaneamente com seus alunos do Ensino Médio os conceitos-chave explorados em cada tópico. 
Este artigo, então, objetivou compartilhar questões próprias da avaliação da aprendizagem, entendimentos (quase consensos) alcançados na reflexão coletiva, que se apresentam como desafios postos ao cotidiano educacional. Entendimentos que, por mais óbvios que pareçam, ainda não se materializam nas práticas avaliativas, mas estão em processo. Para tanto, primeiramente, será abordada a concepção teórica da avaliação da aprendizagem. Em seguida, serão elencados os pontos aqui considerados como os mais relevantes para a elaboração de instrumentos e definição de critérios avaliativos, considerando a visão positiva do erro no processo de aprendizagem e a importância da emissão do feedback para o aluno.

Vale ressaltar que, embora o texto tenha sido elaborado por docentes de Biologia do Ensino Médio, as questões inquietantes sobre avaliação da aprendizagem não estão restritas a essa disciplina, de modo que podem ser aplicadas a qualquer atividade educativa.

\section{Concepção teórica da avaliação da aprendizagem}

Entende-se a avaliação como a materialização de um determinado pensamento pedagógico que está atrelado a uma concepção teórica sobre sociedade, educação e aprendizagem. Logo, dissociar esses elementos ou assumir posturas de neutralidade é um ato de ingenuidade que não findará na verdadeira compreensão do processo avaliativo (LUCKESI, 2001a).

Quanto mais há o amadurecimento das teorias que embasam o processo de ensino-aprendizagem e os estudos sobre a educação, mais se entende que a avaliação, quando comprometida com a aprendizagem, é uma prática desafiadora para o docente, pois pressupõe a compreensão de toda a complexidade da tarefa educacional. É uma prática que não se pauta em juízos subjetivos ou emocionais, mas preocupa-se em buscar diversidade de instrumentos e organizar-se de forma sistematizada.

Luckesi (2011) afırma que a avaliação da aprendizagem ocorre de maneira processual e dinâmica, não de forma pontual e puramente classificatória. Afınal, avaliar é olhar o processo de aprendizagem, o que inclui também avaliar a própria prática avaliativa do docente. Desse modo, o processo avaliativo busca diversos meios que permitam a todos os estudantes efetivamente aprender, caracterizando um ato democrático, e não mais uma forma de exclusão. É democrático porque é inclusivo.

Pensando no contexto atual nacional, a prática de uma avaliação processual se torna ainda mais desafiadora, por vezes utópica, visto que o atual projeto de desmantelamento da educação e de manutenção de precariedade é bastante forte na sociedade brasileira. Quando se fala em educação básica, o panorama é ainda mais fatigante, já que se observa cada vez mais a valorização, por parte dos gestores, de posturas mecanicistas e reprodutoras de uma prática industrial e robotizada, com pouco senso crítico e sem reflexão sobre os conteúdos e conhecimentos. 
Porém a avaliação é um elemento fundamental para nortear o processo de ensino-aprendizagem e retroalimentar as práticas pedagógicas. Identificar, analisar e reconfigurar as atividades e os instrumentos apresentados e desenvolvidos por alunos de Ensino Médio na disciplina de Biologia torna-se essencial para que as formas de avaliação atendam aos princípios de inclusão, acolhimento e integração propostos por Luckesi (2005).

Segundo Hoffmann (2002), nas Ciências, é necessário construir um modo de avaliação que atenda às demandas dessa área do conhecimento, pois o viés da construção do conhecimento e do método científicos é muito evidente. Torna-se imprescindível identificar previamente as representações de mundo dos estudantes e seu contexto social; estimular o raciocínio, ao invés da memorização; instigar a investigação e favorecer a interação sujeito-meio, para que ele se torne consciente de suas ações como cidadão além dos muros da escola. Então, uma das funções da avaliação é diagnosticar o andamento da aprendizagem, para que esse

A avaliação deve se adequar para que prevaleça a qualidade sobre a quantidade resultado embase tomadas de decisões e mudanças ou permanências de estratégias no sentido de melhorar a qualidade do desempenho dos alunos.

De maneira geral, ao avaliar, os professores realizam basicamente três procedimentos para analisar o aproveitamento escolar: coleta de dados acerca do desenvolvimento das aprendizagens; transformação do dado em nota ou conceito; e utilização dos resultados identificados (LUCKESI, 2011). Para a coleta de dados, é preciso considerar a diversidade de instrumentos e, para o julgamento dos dados, que é a transformação do dado em notas ou conceitos, há que se definir muito bem os critérios avaliativos. A utilização dos resultados identificados é feita quando se toma decisão sobre avançar ou retroceder nas intersecções do conhecimento em construção pelos alunos, partindo da visão positiva do erro. Já o uso dos resultados identificados caracteriza-se pela tomada de decisão do professor, representando uma das etapas mais significativas da avaliação, que está diretamente relacionada à prática pedagógica do próprio docente.

Assim, a avaliação deve se adequar para que prevaleça a qualidade sobre a quantidade, a cooperação sobre a competição e a parceria sobre a dominação. Nesse novo contexto, o professor assume um papel construtivista de facilitador e mediador da aprendizagem, de preferência, considerando aspectos afetivos e lúdicos.

Segundo Luckesi (2000a), a avaliação da aprendizagem deve ser amorosa, dinâmica, construtiva e inclusiva, considerando a realidade que cerca o educando, mesmo que esta não the seja favorável. O importante é que a avaliação divirja dos exames que são excludentes, classificatórios e não construtivos. A avaliação inclui, aproxima e é capaz de inserir; os exames selecionam, excluem e marginalizam.

Kishimoto (2002) afirma que a ludicidade favorece o desenvolvimento da inteligência e facilita o estudo, tornando-se uma maneira adequada para a aprendizagem dos conteúdos. O lúdico faz parte do processo de ensinar e propicia ao alu- 
no construir uma aprendizagem consciente e espontânea (RIZZI; HAYDT, 1998). Para Luckesi (2000b), o lúdico promove um desbloqueio no pensamento da criança, do adolescente e do adulto, tornando-os capazes de buscar resultados significativos para sua aprendizagem. Nesse processo, o aluno desempenha um papel ativo, utiliza seus conhecimentos prévios, relacionando-os com o novo conteúdo, analisa, compara e reconstrói seus esquemas de conhecimento em sua estrutura cognitiva (MORTIMER; CARVALHO, 1996), indo ao encontro da perspectiva construtivista.

Vale ressaltar que a avaliação vai muito além da mera atribuição de nota, a qual é apenas uma das variadas maneiras de quantificar o resultado da avaliação. Na medida que se amplia a compreensão da avaliação, a quantificação tende a ter menos importância e se coloca menos difícil o registro do processo avaliativo. 0 interesse maior é, portanto, a aprendizagem do aluno, e não a simples quantificação do registro do resultado em notas.

\section{Instrumentos e critérios de avaliação}

Hoffmann (2002) afirma que a avaliação é uma reflexão permanente sobre a realidade, sendo necessário um acompanhamento da trajetória de construção do conhecimento do aluno. Nesse cenário, o avaliador não julga o avaliado por um único instrumento, um teste, por exemplo, reprovando ou aprovando-o; mas observa os dados obtidos no processo avaliativo com atenção, identificando fragilidades no processo e criando estratégias de superação de limites e ampliação de possibilidades. Daí a importância dos instrumentos de avaliação.

Krasilchik (2008) também atenta para a escolha dos instrumentos que serão utilizados no processo avaliativo, os quais requerem um planejamento coerente e adequado para cada característica avaliativa, pois a diversificação dos instrumentos contribui para maior democratização do conhecimento. Dessa forma, os instrumentos, quanto mais amplos, mais abarcarão os diversos tipos de apropriações sobre a temática trabalhada e serão capazes de absorver o máximo de respostas possíveis para a continuidade do processo.

Fernandes (2008) afirma que os professores devem partilhar o poder de avaliar com os alunos e outros intervenientes e, para isso, utilizar uma variedade de estratégias, técnicas e instrumentos de avaliação. $O$ autor também reforça que a avaliação precisa estar integrada no processo de ensino e aprendizagem e utilizar métodos predominantemente qualitativos, não se pondo de parte a utilização de métodos quantitativos.

O desenvolvimento de instrumentos ou estratégias de avaliação enfrenta vários obstáculos, como a quantidade de conteúdo, a ambiguidade das perguntas e a elaboração de questões voltadas apenas ao conteúdo, não às estratégias que seriam utilizadas na aprendizagem. De acordo com Luckesi (2000a), aplicar provas ou testes e realizar tarefas não é avaliar, e sim coletar informações que podem subsidiar 
a avaliação. A intencionalidade pedagógica transparecerá na definição do plano de avaliação do professor ao definir as estratégias e os instrumentos da avaliação de coleta de dados. Assim, permitirá revelar os pontos fortes e fracos de cada aluno, o que levará o docente a refletir sobre as medidas a serem tomadas para acertar rumos. Nesse ponto reside a importância de o professor buscar elaborar os referenciais que nortearão o processo de ensino-aprendizagem e sua avaliação (DEPRESBITERIS; TAVARES, 2009).

O professor poderá colher as informações por meio de diferentes instrumentos, como pesquisas e apresentações, relatórios de trabalho de campo, visitas, seminários, júris simulados, autoavaliação, mapas conceituais, debates, além das provas. Independentemente do instrumento de avaliação escolhido, é necessário, sobretudo, respeitar características essenciais: ser reflexivo, abrangente, contextualizado, claro, com graus de complexidade variando entre difícil, médio e fácil, compatíveis às necessidades dos alunos. Cada turma apresenta suas particularidades, portanto as avaliações precisam respeitar as peculiaridades, representando a diversidade entre os estudantes.

Na elaboração de instrumentos de avaliação, ao serem feitas questões com clareza, identificar-se-á, objetivamente na resposta, o conhecimento dos alunos cuja aquisição se busca identificar. Por outro lado, não é aconselhável o hábito muito comum de dificultar as perguntas, com o objetivo confundir os alunos, criando as famosas "pegadinhas", em que o aluno, embora possa saber a resposta, erra por não ter entendido o enunciado. É importante que os instrumentos cubram todos os aspectos, considerando o que foi efetivamente discutido e a forma como foi ensinado, e não apenas os mais difíceis. A valoração de cada questão corresponderá ao seu grau de complexidade.

Embora muito se critique o uso da prova, ela pode ser uma estratégia privilegiada, principalmente quando não é o único instrumento e quando o uso de seus resultados vai além da mera classificação dos alunos. Embora a prova escrita, dissertativa, seja a mais comum na Biologia, por apresentar uma série de perguntas, há outros tipos de provas que podem ser explorados.

\section{As avaliações}

precisam respeitar

as peculiaridades, representando a diversidade entre os estudantes
As provas com questões objetivas também são muito usadas, uma vez que se assemelham aos exames vestibulares. Esse tipo caracteriza-se por uma série de perguntas diretas para respostas com apenas uma solução possível. Há outras possibilidades das questões objetivas, por exemplo, o uso de verdadeiro ou falso para que o aluno tenha que julgar proposições. Outras possibilidades são as questões de certo ou errado (C ou E), de correspondência, de lacuna, de ordenação, de correlação etc.

As provas com consulta são semelhantes às dissertativas, diferenciando-se pelo fato de o aluno ter à sua disposição livros ou apontamentos para consultar no momento de realização das provas. Quando bem-elaboradas, possibilitam que o aluno demonstre sua capacidade de pesquisa, de buscar a resposta correta e relevante, além da correlação teoria e prática, indo além da verificação do conhecimento 
sobre o conteúdo objeto da avaliação. Frente ao uso das tecnologias digitais de informação e comunicação no mundo contemporâneo, a capacidade de pesquisa é fundamental e deve ser trabalhada na escola, ou corre-se o risco de continuar com as pessoas se fundamentando em informações baseadas em fake news transmitidas por meio de correntes de WhatsApp.

A prova oral, atualmente, é menos usual, entretanto permite que os alunos exponham seus pontos de vista sobre o conteúdo ou resolvam problemas em contato direto com o professor. Esse tipo de atividade foca o estímulo à oralidade e a habilidade argumentativa.

Já a prova prática é muito usada nas aulas de laboratório de Biologia. Nesse caso, o aluno fica diante de uma situação problemática e precisa encontrar a solução para ela. Por fim, as provas operatórias visam identificar a aplicação do conhecimento, exigindo uma complexidade maior das operações mentais - (re)conhecimento, compreensão, aplicação, análise, síntese e, sobretudo, o julgamento, que está no maior nível de complexidade dentro da taxionomia de Bloom (PERRENOUD, 1999).

O ambiente da aplicação de testes e provas também pode interferir decisivamente nos resultados alcançados, então o ideal é que seja em um clima natural, sem a pressão emocional que envolve as atividades avaliativas. Sabe-se que o estresse emocional tem impacto significativo nas capacidades cognitivas.

A capacidade de pesquisa é fundamental e deve ser trabalhada na escola
Em Biologia, é possível lançar mão de diversos instrumentos avaliativos para que, em conjunto, consiga-se desenhar ao docente a atual posição em que o discente se encontra da forma mais fidedigna possível. Uma prova objetiva, com respostas restritas e previamente direcionadas, por exemplo, terá seu valor em expressar o conteúdo curricular de forma crua e direta. Já um instrumento coletivo, na construção de um debate acerca de um tema diretamente ligado ao currículo, fornecerá dados mais amplos sobre apropriações e reflexões, não somente do que foi trabalhado diretamente nas aulas, mas pondo em pauta a capacidade de abstração e interpretação do aluno a respeito de tais dados fora do espectro apresentado. Uma prática em laboratório, por sua vez, estimula o protagonismo pedagógico (quando bem realizado), permitindo que o aluno, por intermédio do método científico, trabalhe em seus próprios pensamentos e hipóteses acerca de um determinado conteúdo e valide-os.

Uma vez escolhidos os instrumentos, vem a necessidade de reflexão sobre as perspectivas de definição dos critérios que são usados pelos professores para a correção. A correção nada mais é que a leitura dos dados obtidos por meio dos instrumentos. O desempenho de cada aluno pode ser comparado com a média do grupo do qual faz parte ou, então, pode ser analisado tendo como norte os objetivos da aprendizagem. A primeira situação denomina-se avaliação normativa, na qual o desempenho do aluno é comparado ao desempenho médio da turma e seu propósito é classificar por meio da comparação, característica da pedagogia tradicional; a segunda é a avaliação criteriada (ou criterial) e visa às aprendizagens de cada 
aluno em seus percursos singulares, considerando objetivos previamente fixados, informando o que o aluno sabe ou não sabe, o contexto particular e o progresso do estudante ao longo do tempo, diagnosticando os eventuais desvios do esperado, encorajando o discente e promovendo a aprendizagem (FERRAZ; FERNANDES, 1995). A avaliação criteriada está em consonância com a equidade na educação.

No entanto

[...] o diagnóstico é inútil se não der lugar a uma ação apropriada. Uma verdadeira avaliação formativa é necessariamente acompanhada de uma intervenção diferenciada, com isso supõe em termos de meios de ensino, de organização dos horários, de organização do grupo-aula, até mesmo de transformações radicais das estruturas escolares (PERRENOUD, 1999, p. 15).

Segundo Hadji (2001), a intenção dominante do avaliador torna a avaliação formativa, pois, ao situá-la no centro da ação, sua função principal é contribuir para uma boa regulação da atividade de ensino. Para o autor, aqueles que acreditam na necessidade de uma avaliação formativa julgam pertinente o princípio segundo o qual a prática de avaliar deve se tornar auxiliar da prática de aprender. Hadji (2001) considera a avaliação formativa como a ideal, uma vez que não representa uma operação externa de controle, mas propõe uma contribuição à evolução do aluno quanto ao que ele já possui, representando uma continuidade ao processo pedagógico. Ele afirma que avaliar não é medir, mas, sim, construir dialogicamente um processo de negociação, de modo que aluno e professor possam tomar consciência de suas dificuldades, bem como reconhecer e "corrigir" suas ações. Fernandes (2008) reforça que a avaliação deve servir mais para ajudar as pessoas a desenvolverem suas aprendizagens do que para julgá-las ou classificá-las em uma escala.

A observação significativa do olhar do docente pode ser registrada em cadernos de campo, em fichas de anotações para cada grupo de alunos ou para cada aluno individualmente, nos diários do aluno, em arquivos de atividades ou, ainda, na construção de portfólios de aprendizagem. Atualmente, os dispositivos móveis são excelentes recursos para registro do processo dos estudantes.

\section{A visão positiva do erro}

La Taille (1997), apoiado em fundamentos de Piaget, explica o processo de desenvolvimento cognitivo com base nos conceitos de assimilação, acomodação e equilíbrio. Dessa forma, a realização de atividades avaliativas pode promover desequilíbrios no sistema cognitivo do aprendente. Quando há a identificação dos acertos, há a continuidade do processo; mas quando se identificam erros, há que ser realizado um trabalho cooperativo entre educando e educador, de modo a construir novos mecanismos de apropriação. A essa concepção dá-se o nome de visão positiva do erro. Por exemplo, ao se encarar a resposta "mitocôndria serve para fazer fotossíntese", observa-se que conhecimentos distintos (mitocôndria e fotossíntese) 
encontram-se conectados de modo errado e deverão ser ressignificados, sem a necessidade de apenas expor o erro, pois, dessa maneira, os conceitos internalizados pelo discente não serão remodelados.

Utiliza-se a correção para que o professor identifique as qualidades e dificuldades apresentadas pelos alunos. No entanto, ao encontrar erros, é necessário dar ênfase a eles e, a partir disso, desenvolver estratégias que os corrijam. Os equívocos cometidos em uma avaliação levam o aluno a transformar seus esquemas cognitivos, pois evidenciam um aspecto em que ele pode melhorar. É fundamental que o aluno analise o que acertou, bem como perceba seus erros, a fim de superá-los. Para que isso ocorra de modo efetivo, é importante que haja um feedback do professor para os alunos.

\section{A importância do feedback}

O termo feedback origina-se da Biologia em referência ao processo de resposta que o organismo fornece após interagir em seu ambiente (FLUMINHAN; ARANA; FLUMINHAN, 2013). Na educação, o feedback pode ser entendido como a estratégia de comunicação dos resultados aos discentes, sejam positivos, sejam negativos.

Para que um feedback seja assertivo, é preciso ir além de uma aferição de conotação numérica
No processo avaliativo, o feedback é um dos principais elementos quando a avaliação está a serviço da aprendizagem dos alunos, uma vez que permitirá a identificação dos nós da aprendizagem. A percepção das lacunas possibilita que os alunos promovam novas interpretações acerca do conhecimento, resultando em novas conexões, propostas e soluções. De acordo com Fernandes (2008), o feedback, em suas diferentes formas, frequências e distribuições, é indispensável para a integração da avaliação ao processo de ensino e aprendizagem.

Para que um feedback seja assertivo, é preciso ir além de uma aferição de conotação numérica. É necessário que faça sentido para o aluno e represente uma devolutiva pautada em discussões, retomada de critérios, adequações ou inadequações das produções. Para Zeferino, Domingues e Amaral (2007, p. 178), para sua efetividade, o feedback deve ser:

(1) Assertivo. A comunicação dever ser clara, objetiva e direta. Por temer o impacto das palavras, o professor pode não ser direto, falando de forma vaga, com afirmações ambíguas que ofuscam a mensagem principal. 0 aluno, temendo uma avaliação negativa, não procura esclarecimentos, reforçando a falta de clareza do professor. Como resultado, apesar das intenções educativas, pouco é transmitido. Assim, recomenda-se descrever os impactos e consequências de determinado comportamento, positivos ou negativos, assim como sugerir comportamentos alternativos. (2) Respeitoso. Este é um elemento fundamental para o sucesso do feedback, independentemente das diferenças de conhecimento, experiência, hierarquia ou características pessoais entre 
os interlocutores. Como é um processo compartilhado, docente e aluno devem encontrar pontos de concordância sobre os comportamentos que devem ser trabalhados; entender e respeitar a opinião do outro geram o ambiente de respeito para um feedback construtivo. (3) Descritivo. Embora o estudante, em geral, esteja ávido por ouvir a opinião dos professores, sua reação é menos resistente quando as palavras descrevem determinado comportamento ou ação, ao invés de julgá-lo. (4) Oportuno. O momento e o local para dar feedback ao aluno devem ser adequados, preferencialmente logo após a observação do comportamento e em ambiente reservado. (5) Específico. É fundamental que o docente indique claramente os comportamentos nos quais o aluno está tendo bom desempenho e aqueles nos quais o aluno pode melhorar. Exemplos e revisão dos fatos ocorridos contribuem para que o aluno reflita honestamente sobre seu desempenho (ZEFERINO; DOMINGUES; AMARAL, 2007, p. 178).

Somente buscando um acompanhamento continuado das descobertas educacionais sobre a avaliação da aprendizagem o professor poderá aproximar-se mais de um processo avaliativo que contribua positivamente para a vida dos alunos. Com um processo de ensino-aprendizagem real, reduzem-se as injustiças e incoerências, e o estímulo ao fracasso é substituído pela promoção ao êxito.

\section{Considerações finais}

A escola, muitas vezes, em sua maneira tradicional de avaliação, utiliza critérios predeterminados que emperram a prática avaliativa, voltando-se muito mais ao simples cumprimento de questões burocráticas, desconsiderando seu valor pedagógico. Essa burocratização, frequentemente, parte de instâncias superiores que corroboram a pedagogia do exame.

A partir do momento em que se reflete sobre o real sentido da avaliação da aprendizagem na prática educacional, torna-se possível compreender que a ação de avaliar carrega consigo a grande responsabilidade da democratização do conhecimento, da cultura e da vida social, oportunizando o sucesso para os envolvidos. A importância da análise dos erros e do feedback a partir dos resultados encontrados está justamente no sentido de possibilitar intervenção e reorientação do processo de ensino-aprendizagem, visto que é uma construção, tanto para a prática pedagógica do professor quanto para o educando, até que o estudante consiga desenvolver-se de forma satisfatória, tornando-se protagonista no percurso de aprendizagem. Ao longo de todo processo avaliativo, que, de forma inexorável, faz parte do cotidiano docente, o propósito deve ser contribuir com a reflexão coletiva, por meio da observação minuciosa e da crítica construtiva, estimulando a autonomia e corresponsabilização dos resultados.

A avaliação é um dos principais mecanismos do processo de ensino-aprendizagem emancipador quando não é encarada como algo finito, único e punitivo. Pontuações, 
provas unificadas, murais de destaque, rankings e outros critérios podem ser trabaIhados em conjunto com a prática avaliativa, porém sempre agregados a reflexões. A avaliação é, antes de tudo, um trabalho constante de análise, continuidade e remodelagem, e o educador inclui-se nesse processo de construção, traçando novos rumos de sua prática, a partir dos resultados obtidos, por tantas vezes quanto for necessário.

Embora não sejam compartilhados neste artigo conhecimentos propriamente novos à matéria do ponto de vista teórico, as questões apresentadas foram consideradas como "descobertas" do ponto de vista do docente que está em sala de aula. Talvez por subestimar a importância da disciplina de avaliação nas licenciaturas, talvez por não terem vivenciado práticas avaliativas emancipadoras e, assim, fica uma importante reflexão para os cursos de formação docente.

Após a realização da disciplina Avaliação da Aprendizagem, foi possível A avaliação, antes de tudo, é um trabalho observar, pela autoavaliação e por meio de relatos, mudanças nos modelos de avaliação aplicados pelos mestrandos do Profbio, que também são professores das redes pública e privada, bem como o reflexo dessas novas estratégias em seus alunos. Ao compreenderem a importância de uma avaliação formativa e democrática, esses professores transformaram o modo de olhar o processo avaliativo ao qual submetiam seus estudantes, reformulando as atividades, entendendo a diferença entre teste/prova e avaliação, oferecendo feedback aos alunos e aproveitando os erros, antes descartados ou diminuídos, para construir novos momentos de aprendizagem.

Um dos instrumentos avaliativos que mais trouxe mudanças atitudinais nos discentes de Biologia foi o uso de autoavaliação contendo questões relacionadas à assiduidade, entrega de atividades, respeito aos prazos, bom relacionamento com colegas de sala, e zelo pelo ambiente escolar, entre outros, uma vez que, ao construírem coletivamente os critérios pelos quais se autoavaliariam, os mesmos transformaram seus comportamentos positivamente. Dessa maneira, a autoavaliação é uma ferramenta por meio da qual o estudante pode olhar para si mesmo e para seus atos, assumir a responsabilidade por eles, reconhecer suas qualidades positivas e negativas e, se necessário, promover mudanças.

Considerando todas as informações apresentadas, cabe aos cursos de formação inicial e continuada de professores, assim como ao Mestrado Profissional em Ensino de Biologia, propor momentos que contribuam com a reflexão sobre a prática docente e a forma como é compreendido o papel da avaliação da aprendizagem de alunos. De preferência, que esses processos também sejam vivenciados no decorrer do curso, o que nem sempre acontece. Estimular que os professores assumam uma visão crítica e consciente de todo o potencial da avaliação, transformando-a em algo processual que considera a realidade na qual o estudante está inserido e seus conhecimentos prévios, parece ser um dos caminhos a uma aprendizagem significativa e ao desenvolvimento do protagonismo estudantil tão almejados pelos educadores. 


\section{Referências}

BRASIL. Ministério da Educação. Secretaria de Educação Básica. Ciências da natureza, matemática e suas tecnologias. Brasília, DF: Ministério da Educação, Secretaria de Educação Básica, 2006. (Orientações curriculares para o ensino médio, v. 2).

MORTIMER, Eduardo Fleury; CARVALHO, Anna Maria Pessoa de. Referenciais teóricos para análise do processo de ensino de Ciências. Caderno de Pesquisa, São Paulo, n. 96, p. 5-14, fev. 1996.

DEPRESBITERIS, Léa; TAVARES, Marialva Rossi. Diversificar é preciso...: instrumentos e técnicas de avaliação e aprendizagem. São Paulo: Editora Senac São Paulo, 2009.

FERNANDES, Domingos. Avaliação das aprendizagens: desafios às teorias, práticas e políticas. Lisboa: Texto Editores, 2008.

FERRAZ, Maria José; FERNANDES, Domingos. Pensar avaliação, melhorar a aprendizagem. Lisboa: Instituto de Inovação Educacional, 1995.

FLUMINHAN, Carmen Silva Lima; ARANA, Alba Regina Azevedo; FLUMINHAN, Antonio. A importância do feedback como ferramenta pedagógica na educação a distância. Colloquium Humanarum, [s. I.], v. 10, n. especial, p. 721-728, jul./dez. 2013.

FREIRE, Paulo. Pedagogia da autonomia: saberes necessários à prática educativa. São Paulo: Paz e Terra, 1996.

HADJI, Charles. A avaliação desmistificada. Porto Alegre: ARTMED, 2001.

HOFFMANN, Jussara. Avaliação: mito e desafio: uma perspectiva construtivista. 30. ed. Porto Alegre: Mediação, 2002.

KISHIMOTO, Tizuko Morchida (org.). O brincar e suas teorias. São Paulo: Pioneira, 2002.

KRASILCHIK, Myriam. Prática de ensino de Biologia. 4. ed. rev. e ampl. São Paulo: EDUSP, 2008.

LA TAILLE, Y. J. J. M. R. O erro na perspectiva piagetiana. In: AQUINO, Juliano. Gropa (org.). Erro e fracasso na escola: alternativas teóricas e práticas. São Paulo: Summus, 1997.

LUCKESI, Cipriano Carlos. Avaliação da aprendizagem escolar. 11. ed. São Paulo: Cortez, 2001a. 
LUCKESI, Cipriano Carlos. Avaliação da aprendizagem escolar: estudos e proposições. 19. ed. São Paulo: Cortez, 2011.

LUCKESI, Cipriano Carlos. Avaliação da aprendizagem escolar: uma opção pela vida. In: FERREIRA, V. S. Educação: novos caminhos em um novo milênio. Natal: Autor Associado, 2001b.

LUCKESI, Cipriano Carlos. Avaliação da aprendizagem na escola: reelaborando conceitos e criando a prática. 2. ed. Salvador: Malabares Comunicações e Eventos, 2005.

LUCKESI, Cipriano Carlos. O que é mesmo o ato de avaliar a aprendizagem? Pátio On-line, Porto Alegre, ano 3, n. 12, fev./abr. 2000a.

LUCKESI, Cipriano Carlos (org.). Ensaios de ludopedagogia. Salvador: UFBA/ Faced, 2000b.

PERRENOUD, Phillipe. Avaliação: da excelência à regulação das aprendizagens: entre duas lógicas. Porto Alegre: Artes Médicas Sul, 1999.

RIZZI, Leonor; HAYDT, Regina Celia. Atividades lúdicas na educação da criança. 7. ed. São Paulo: Ática, 1998.

TEIXEIRA, Paulo Marcelo Marini. Educação científica e movimento CTS no quadro das tendências pedagógicas no Brasil. Revista Brasileira de Pesquisa em Educação em Ciências, Porto Alegre, v. 3, n. 1, p. 88-102, 2003.

ZEFERINO, Angelica Maria Bicudo; DOMINGUES, Rosângela Curvo Leite; AMARAL, Eliana. Feedback como estratégia de aprendizado no ensino médico. Revista Brasileira de Educação Médica, Rio de Janeiro, v. 31, n. 2, p. 176-179, 2007.

\section{Fontes consultadas}

AUSUBEL, David. P.; NOVAK, Joseph. D.; HANESIAN, Helen. Psicologia educacional. 2. ed. Rio de Janeiro: Editora Interamericana, 1980.

CABRERA, Waldirléia Baragatti. A ludicidade para o ensino médio na disciplina de Biologia: contribuições ao processo de aprendizagem em conformidade com os pressupostos teóricos da aprendizagem significativa. 2007. Dissertação (Mestrado em Ensino de Ciências e Educação Matemática) - Universidade Estadual de Londrina, Londrina, 2007. 
LUCKESI, Cipriano Carlos. Avaliação educacional: pressupostos conceituais.

Tecnologia Educacional, Rio de Janeiro, v. 7, n. 24, p. 5-8, 1978.

MYAZAWA, Fernando Mori; URSI, Suzana. Avaliação da aprendizagem de conceitos ecológicos a partir da sequência didática "Biomas Brasileiros". Revista SBEnBio, [Campinas, SP] n. 3, out. 2010.

REMPEL, Claudete; STROHSCHOEN, Andreia Aparecida Guimarães; GERSTBERGER, André; DIETRICH, Franciele. Percepção de alunos de ciências biológicas sobre diferentes metodologias de ensino. Revista Signos, Lajeado, ano 37, n. 1, p. 82-90, 2016. 